\title{
Development of New Neuromuscular Blocking Agents
}

\author{
Hiroshi Sunaga $\cdot$ Cynthia A. Lien
}

Published online: 29 March 2013

(C) Springer Science + Business Media New York 2013

\begin{abstract}
Increased understanding of structure-activity relationships has allowed the development of neuromuscular blocking compounds and reversal agents that are unique and offer pharmacokinetic and dynamic improvements over their predecessors. Compounds have been developed that have a short duration of effect, a rapid clearance and a decrease in adverse effects. The fumarates comprise one of the series of compounds that have resulted from this research. These compounds are inactivated through a mechanism that is completely new for neuromuscular blocking agents-that of cysteine adduction. The work has also led to the development of alternative ways to enhance recovery of neuromuscular function. Sugammadex encapsulates steroidal neuromuscular blocking compounds making them unable to interact with the acetylcholine receptor and reversing their effect within minutes. Recovery from gantacurium- or CW002-induced neuromuscular block can be shortened by administration of L-cysteine. These new neuromuscular blocking and reversal agents allow for maintenance of an adequate depth of neuromuscular block intraoperatively and almost immediate recovery of neuromuscular function, a sensible goal as the risks of residual neuromuscular block are increasingly appreciated.
\end{abstract}

Keywords Fumarates - Gantacurium - CW002 .

L-Cysteine

\section{Introduction}

In an editorial in 1975, Savarese and Kitz [1] described the need for new neuromuscular blocking agents. In that article a

H. Sunaga · C. A. Lien $(\bowtie)$

Department of Anesthesiology, Weill Cornell Medical College, 525 East 68th Street, New York, NY 10065, USA

e-mail: calien@med.cornell.edu need for neuromuscular blocking agents with three different pharmacodynamic profiles was outlined: there was a need for a short-acting compound with a rapid onset of effect, an intermediate-acting compound that had no cumulative effects and a long-acting compound that was free of hemodynamic side effects. Since then, many compounds have been introduced into clinical practice that have met several facets of the requirements described in 1975. Identification of the short-acting compound with a rapid onset of effect though, remains elusive and, for this reason, of the compounds available for use in 1975 , succinylcholine, is the one that is still used commonly in clinical practice.

Succinylcholine has been available since 1952 in the US. It was the one of the earliest neuromuscular blocking agents introduced into clinical practice-following the introduction of d-tubocurarine ten years earlier [2, 3]. As a depolarizing neuromuscular blocking agent, it offered a pharmacodynamic profile that was very different than that of its nondepolarizing predecessors and was rapidly incorporated into clinical practice. Because of the combination of its rapid onset of effect and short duration of action, it is still-in spite of its adverse effect profilecommonly used in clinical practice.

The well-known adverse effects of succinylcholine, which range from fasciculations to hyperkalemia and cardiac arrest, are largely attributable to its depolarizing nature of action and have continued to fuel an interest in finding a nondepolarizing equivalent. Additionally, as quantitative monitors of neuromuscular block have become increasingly available and the adverse of residual neuromuscular block more appreciated, there is a renewed interest in identifying compounds that will allow for reliable and complete recovery of neuromuscular function.

Identification of several key compounds has provided essentially the building blocks to allow development of 
neuromuscular blocking agents to move forward. Development of these key neuromuscular blocking agents will be briefly reviewed as an understanding of their structureactivity relationships has contributed to the development of the newest compounds.

\section{Onset of Neuromuscular Block}

Impact of Mechanism of Neuromuscular Block on Onset of Neuromuscular Block

The rapid onset of succinylcholine-induced block has been attributed to a combination of four different factors; its mechanism of action, its potency, its clearance, and the dose administered for a rapid sequence induction. In the 1990's Feldman theorized that, while a nondepolarizing neuromuscular blocking agent had to block $80 \%$ of receptors for the block to occur, a depolarizing agent could cause a block with occupancy of less than $20 \%$ of receptors [4]. Shortly thereafter, in a comment on the inherent margin of safety in neuromuscular transmission, Fauvel [5] stated that "if block occurs with 75-90\% occupancy, twitch requires only 10-25\% occupancy". As the adverse effects of succinylcholine are due to the depolarizing nature of its block, this has not been a characteristic sought in new neuromuscular blocking agents.

\section{Impact of Potency on Onset of Neuromuscular Block}

Paton and Waud [6] found that neuromuscular block was not detectable until $80 \%$ of acetylcholine receptors had been blocked and that neuromuscular block was maximal once $90 \%$ of receptors had been bound by a nondepolarizing neuromuscular blocking agent. Because of the concentration of acetylcholine receptors at the neuromuscular junction and the percentage of these receptors that have to be blocked before a decrease in muscle strength is appreciable, potency of a neuromuscular blocking agent will impact its onset of effect. Since fewer molecules of a compound are administered when a potent neuromuscular blocking agent is used, there is less of a driving force to move these molecules into the neuromuscular junction where they will have their effect.

Succinylcholine is not a potent neuromuscular blocking agent. Its lack of potency contributes to its rapid onset of effect. Its $\mathrm{ED}_{95}$ has been reported to be between 0.3 and $0.63 \mathrm{mg} / \mathrm{kg}[7,8]$. The relationship between slower onset and greater potency has been demonstrated with steroidal neuromuscular blocking agents [9], benzylisoquinoliniums [10] and equipotent doses of long acting neuromuscular blocking agents of different structures [11].
Impact of Clearance on Onset of Neuromuscular Block

Clearance is another factor postulated to contribute to the speed of onset of neuromuscular block. In an article describing the onset of neuromuscular blocking agents, Bevan stated that "if drug metabolism or redistribution is very rapid, plasma concentrations will decrease quickly so that the time to equilibration of the drug in the effect compartment occurs rapidly" [12]. A study of the concentration effect of succinylcholine demonstrated that it had a rapid clearance $(37 \mathrm{ml} / \mathrm{min} / \mathrm{kg})$ and a short elimination half-life of less than $1 \min$ [13]. As the $k_{\mathrm{e} 0}$ values were similar to what is found for nondepolarizing neuromuscular blocking agents, the rapid onset of effect of succinylcholine was found to be due to its rapid clearance. As anticipated from the relationship between clearance and onset, when succinylcholine is administered to patients who are homozygous for atypical butyrylcholinesterase, its onset of effect is slower than it is in patients with normal enzymatic activity [14].

\section{Recovery of Neuromuscular Function}

The ultrashort-duration of action of succinylcholine is recognized as an advantage in the "cannot intubate-cannot ventilate" scenario. A similar pattern of recovery of neuromuscular function would also be of benefit after a routine general anesthetic in which neuromuscular blockade had been administered and maintenance of neuromuscular blockade was not required. The impact of subtle degrees of neuromuscular block on a patient's ability to breath was described in the 1970s by Ali et al. [15]. Observed changes were small and determined to be clinically insignificant. Approximately ten years later, small precurarizing doses of nondepolarizing agents were noted to cause measurable decreases in the train-of-four response to stimulation. Importantly, these slight changes in response to neuromuscular stimulation were associated with, in addition to visual disturbances, a feeling of malaise and a sense that it was difficult to breathe and swallow [16, 17]. Considerably later, the potential adverse effects of residual neuromuscular blockade during and after emergence from general anesthesia were explored. The adverse effects of residual neuromuscular block, ranging from visual disturbances, to hypoxia in the PACU to aspiration and decreased patient satisfaction, have now been documented in several studies [18-20, 21••, 22••]. Perhaps more importantly, clinicians are beginning to recognize that a train-of-four ratio of $\geq 0.90$ prior to extubation of a patient's trachea, is important in the care of their patients [23]. A number of factors currently render this goal difficult, if not impossible, to obtain. They include a lack of wide spread availability of 
quantitative monitors of neuromuscular function, a nondepolarizing neuromuscular blocking agent with an ultrashort duration of action and, in the United States, a reversal agent that will quickly antagonize any depth of neuromuscular block.

\section{Newer Neuromuscular Blocking Agents}

Over the previous 25 years, development of several new neuromuscular blocking agents and one selective relaxant binding agent have contributed to understanding of the structural elements required to create a nondepolarizing neuromuscular blocking agent that does not cumulate, has a rapid onset of effect and is free of adverse side effects. The intermediate-acting compounds, vecuronium and atracurium, were both introduced in the 1980s. Both had shorter elimination half-lives than any nondepolarizing neuromuscular blocking agent previously available. Vecuronium is very similar to pancuronium in its structure. However, its different pharmacodynamic characteristics were due to the removal of the quaternizing methyl group at the 2-piperidine substitution. Its duration of action was shortened, its renal elimination decreased, and its metabolism in the liver increased when compared to pancuronium. Importantly, the hemodynamic effects of pancuronium were eliminated with the structural revision of the compound [24]. In fact, vecuronium set a new standard for absence of hemodynamic effects- that has only been matched by the development of the long-acting compound pipecuronium. The development of atracurium introduced an entirely new means for these compounds to be inactivated in ways other than end-organ metabolism. The short elimination half-life and rapid clearance of atracurium was due to Hoffman elimination and ester hydrolysis [25]. While it caused histamine release like the benzylisoquinolines that preceded it, d-tubocurarine and metocurine, its propensity to do so was considerably decreased [26].

The second generation of intermediate-acting compounds, cisatracurium and rocuronium, reflects both improvements in the capacity to manufacture a single isomer of a compound on a large scale and an appreciation of the impact of potency on the onset of neuromuscular blockade. In developing rocuronium, the steroidal structure was revised to incorporate different cyclic substitutions at the 2 and 16 positions of the molecule so that its potency for neuromuscular blockade was decreased. While an $\mathrm{ED}_{95}$ is $0.3 \mathrm{mg} / \mathrm{kg}$ [27-29], it is a relatively impotent neuromuscular blocking agent and remains the only available compound with an onset of effect similar to that of succinylcholine [30]. Administration of $0.6 \mathrm{mg} / \mathrm{kg}$ rocuronium $\left(2 \times\right.$ the $\left.\mathrm{ED}_{95}\right)$ causes $100 \%$ neuromuscular block in, on average, $1.5 \mathrm{~min}$. Doubling the dose shortens the onset to just under a minute, comparable to $1 \mathrm{mg} / \mathrm{kg}$ succinylcholine. Not unexpectedly, as the dose of rocuronium is increased to shorten its onset of effect, its duration of action becomes increasingly prolonged. The clinical duration of action (the time from administration of the neuromuscular blocking agent to $25 \%$ recovery of twitch height) is essentially doubled from 37 to $73 \mathrm{~min}$ by increasing the dose from 0.6 to $1.2 \mathrm{mg} / \mathrm{kg}$ [30]. Of note, $25 \%$ twitch height is the earliest point at which antagonism of residual neuromuscular block should be considered.

Cisatracurium, one of 10 isomers of atracurium, is an example of the potential impact of the selection of a structural element on the pharmacodynamics and adverse effect profile of a neuromuscular blocking agent. Cisatracurium is the $1-\mathrm{R}-c i s, 1-\mathrm{R}^{\prime}$-cis isomer that constitutes $10 \%$ of the isomers of which atracurium is composed. With an $\mathrm{ED}_{95}$ of $0.05 \mathrm{mg} / \mathrm{kg}$ [31], it is significantly more potent than atracurium. Because of its potency, its onset is, not surprisingly, substantially slower than that of atracurium. Like atracurium, it undergoes Hofmann elimination. Interestingly, it does not, even when administered rapidly in large doses, cause the release of histamine [32] — making it unique among the benzylisoquinoliniums in terms of its side effect profile.

Development of the short-acting neuromuscular blocking compound, mivacurium, introduced yet another means of metabolizing nondepolarizing compounds. Like succinylcholine, it is metabolized by butyrylcholinesterase. Its clearance is faster than that of succinylcholine [33]. Its clearance is due to the rapid metabolism of its potent cistrans and trans-trans isomers by butyrylcholinesterase. In spite of its clearance, its onset of effect is slower than that of succinylcholine [34]. Its slower onset of effect, in spite of its more rapid clearance, has been attributed to its greater potency [12]. Administration of larger doses to shorten onset of neuromuscular block is limited by the histamine release caused with administration of doses larger than $2.5 \times \mathrm{ED}_{95}$ [35].

Rapacuronium was the most recent neuromuscular blocking agent to be introduced into clinical practice in the USA. Like succinylcholine and rocuronium, it had a rapid onset of effect. Although the duration of action was not as short as that of succinylcholine, it was shorter than that of mivacurium [36]. Its $\mathrm{ED}_{90}$ of $1 \mathrm{mg} / \mathrm{kg}$ meant that it was not a potent neuromuscular blocking agent. Given this, its onset following administration of $1.5 \mathrm{mg} / \mathrm{kg}$, of approximately 1 min was not unexpected. In addition to its low potency as a neuromuscular blocking agent, the rapid clearance of rapacuronium contributed to its rapid onset of effect. Its clearance of $8 \mathrm{ml} / \mathrm{kg} / \mathrm{min}$ [37] is almost twice that of the intermediate-acting neuromuscular blocking agents cisatracurium and vecuronium. 
From a pharmacodynamic point of view, this was a very interesting and promising compound. In clinically relevant doses, however, rapacuronium interacted with the $\mathrm{M}_{2}$ receptors and the $\mathrm{M}_{3}$ receptors of the airway. This meant that the negative feedback of $\mathrm{M}_{2}$ muscarinic acetylcholine receptors of the airway on parasympathetic nerves was inhibited, resulting in excessive release of acetylcholine [38], stimulation of the $\mathrm{M}_{3}$ receptors and bronchoconstriction. Additionally, rapacuronium caused allosteric potentiation of $\mathrm{M}_{3}$ muscarinic acetylcholine receptors on the smooth muscles of the airway, also contributing to bronchoconstriction [39]. With administration of clinicallyrecommended doses of rapacuronium, the observed increase in pulmonary artery pressures is due to its effects on $\mathrm{M}_{2}$ and $\mathrm{M}_{3}$ muscarinic acetylcholine receptors [40, 41]. Rapacuronium was withdrawn from the market in 2001, shortly after its introduction into practice.

\section{New Means of Reversing Neuromuscular Block}

Sugammadex is a selective relaxant binding agent, that encapsulates rocuronium rendering it inactive in the plasma and unable to bind to the acetylcholine receptor at the neuromuscular junction [42, 43]. While anticholinesterases cannot effectively antagonize profound neuromuscular block, sugammadex can reverse profound rocuroniuminduced block [44, 45]. Its dynamics have been welldescribed. When administered 3 min after administration of an intubating dose of rocuronium, recovery of neuromuscular function occurs very quickly - as if rocuronium were a short-acting neuromuscular blocking agent [44]. The rocuronium-sugammadex complex is eliminated through renal mechanisms [46]. As one molecule of sugammadex binds one molecule of rocuronium, it is possible to give an inadequate dose of sugammadex to completely reverse neuromuscular block [47, 48•]. Doses of 8-16 mg/ $\mathrm{kg}$ have been recommended for rapid reversal of profound neuromuscular block.

Its unique means of activity means that this cyclodextrin may have other uses clinically. Neuromuscular blocking agents are the most common causes of anaphylaxis during clinical anesthesia, and rocuronium is the nondepolarizing neuromuscular blocking agent most frequently implicated in these anaphylactic reactions. [49-51]. Since sugammadex encapsulates rocuronium, which is the allergen, it could be another form of treatment [52-55]. Interestingly, though, studies failed to demonstrate the efficacy of sugammadex in the setting of anaphylaxis [56•, 57]. In addition, there have been reports of allergic reaction to sugammadex [58, 59] and 48 cases of anaphylaxis or anaphylactoid reaction in reaction to sugammadex were been reported between April, 2010 through January, 2012 in Japan. This being said, more than 1 million patients have received sugammadex to reverse neuromuscular block induced with rocuronium or vecuronium without occurrence of an adverse event.

Because of the cost of sugammadex, should it be introduced into practice in the United States, it is unlikely that it will be rapidly incorporated into routine clinical practice. It is more likely that it will be used in the "cannot intubate-cannot ventilate" scenario or in cases where a surgical procedure ends far sooner than had been anticipated.

\section{Ongoing Development of Neuromuscular Blocking and Reversal Agents}

The search for an ideal neuromuscular blocking agent is ongoing. A majority of recent work has focused on the development of a new series of fumarate, olefinic isoquinolinium diester, compounds. Within this class of compounds are agents that have varying potency, different onsets of effect and durations of action and different side effect profiles. All are inactivated through a unique mechanism, that of adduction of L-cysteine (Fig. 1). Two of these compounds have undergone volunteer trials.

\section{Gantacurium}

\section{Structure}

Gantacurium (Fig. 1) is an asymmetrical isoquiolinium diester of chlorofumaric acid [60]. Gantacurium rapidly combines with L-cysteine in vitro to form a presumably less-active degradation product (a cysteine adduct) [61 ••]. One of the central double-bonded (olefinic) carbons is activated (so that it has an increased electrophilic character) by a strongly electronegative chlorine substitution that was designed to accelerate the adduction reaction. Gantacurium itself and its adduct may undergo further breakdown by nonenzymatic alkaline hydrolysis.

\section{Pharmacology}

Gantacurium, the first of the olefinic isoquinolinium diester compounds to be studied in humans, is a nondepolarizing neuromuscular blocking agent with $\mathrm{ED}_{95}$ that was $0.19 \mathrm{mg} /$ $\mathrm{kg}$ [62]. It has a rapid onset of effect, resulting in maximal block in $90 \mathrm{~s}$ following administration of $0.3 \mathrm{mg} / \mathrm{kg}(1.5 \times$ the $\mathrm{ED}_{95}$ ) and $60 \mathrm{~s}$ following $0.3-0.4 \mathrm{mg} / \mathrm{kg}$. This rapid onset is likely due to its relative lack of potency as well as its rapid clearance [62]. Following administration of $0.54 \mathrm{mg} / \mathrm{kg}$, onset of $100 \%$ block at the laryngeal 


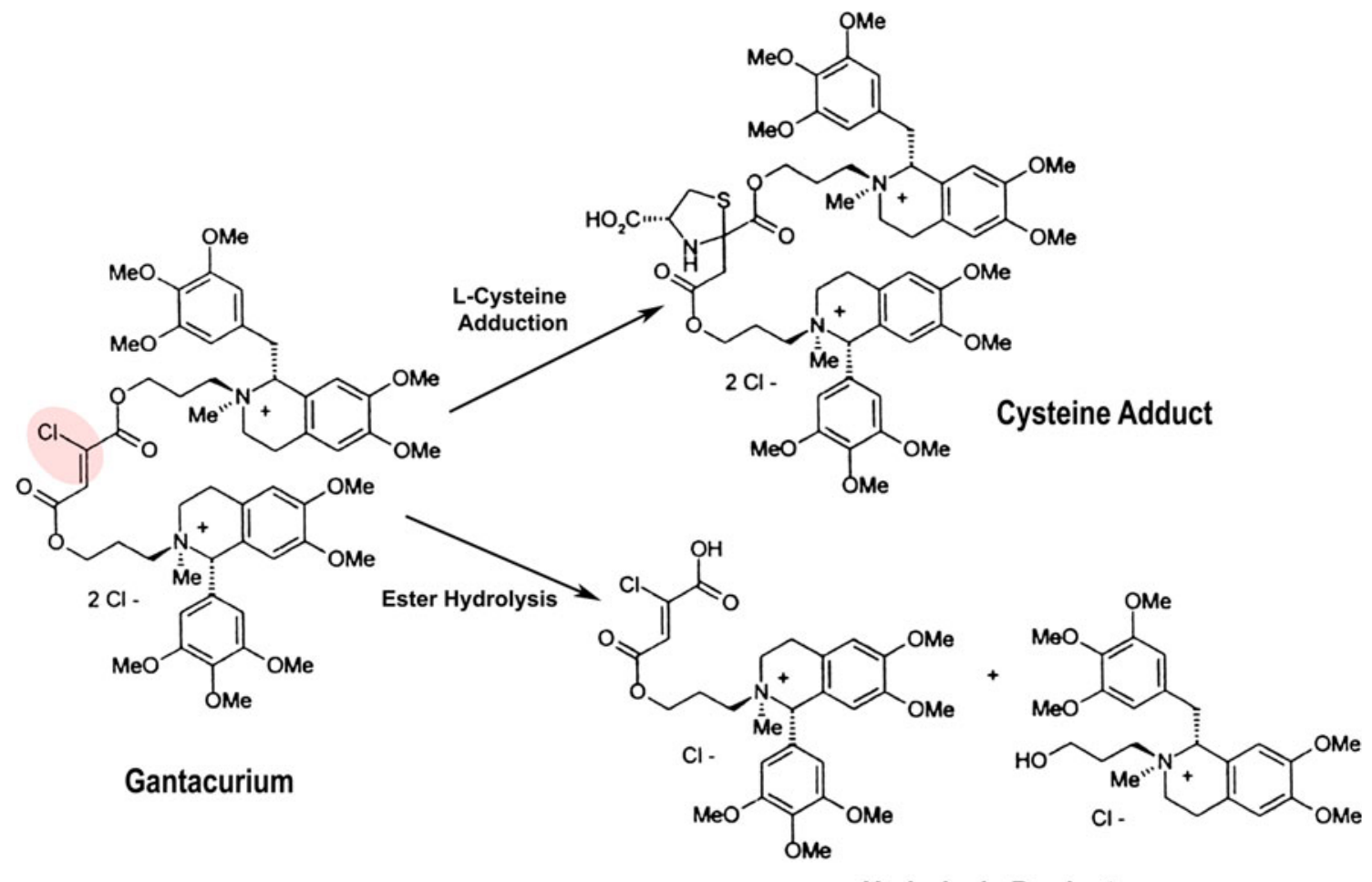

Hydrolysis Products

Fig. 1 The chemical structure of gantacurium (GW 280430A) and its breakdown products. Inactivation takes place at the olefinic bond (indicated by the red circle) through adduction of cysteine in a rapid reaction to yield an adduct. A slower process of inactivation occurs

adductors occurred in 0.9 min while that following $1 \mathrm{mg} /$ $\mathrm{kg}$ succinylcholine was $0.8 \mathrm{~min}\left[63^{\circ}\right]$. Increasing the dose of gantacurium from 0.3 to $0.72 \mathrm{mg} / \mathrm{kg}$ did not change the total duration of action (minutes from administration to a train-of-four ratio $\geq 0.9$ ) of the neuromuscular blocking agent which remained at 14-15 min. Similarly, the 5-95\% recovery interval (the time from $5 \%$ recovery of the first response in the train-of-four to $95 \%$ recovery) remained constant at $7 \mathrm{~min}$ in this dose range.

\section{Reversal}

The ultra-short duration of action of gantacurium is likely due to the adduction of endogenous L-cysteine. This rapid recovery can be further shortened by the administration of edrophonium. When edrophonium, $0.5 \mathrm{mg} / \mathrm{kg}$, was administered at $10 \%$ recovery of $\mathrm{T} 1$, the total duration of action of gantacurium, $0.4 \mathrm{mg} / \mathrm{kg}$, was shortened from 15.5 to $5.7 \mathrm{~min}$. When edrophonium was administered to monkeys $1 \mathrm{~min}$ after gantacurium, it was not as effective a reversal agent. In contrast, when L-cysteine, $10 \mathrm{mg} / \mathrm{kg}$, was administered to monkeys $1 \mathrm{~min}$ after $0.5 \mathrm{mg} / \mathrm{kg}$ gantacurium, $5 \times$ $\mathrm{ED}_{95}$, it rapidly restored neuromuscular function, reducing the total duration of action from 10.4 to 3.0 min (Fig. 2). When administered at the very beginning of recovery, $2 \%$ through hydrolysis to yield two hydrolysis products. From Savarese et al. [60], with permission from Wolters Kluwer Health (Color figure online)

twitch height, exogenous L-cysteine also significantly shortened recovery of neuromuscular function $[61 \bullet \cdot]$.

\section{Adverse Effects}

While gantacurium will, when administered in doses of approximately 3-4× $\mathrm{ED}_{95}$, cause histamine release and its associated hemodynamic changes [62], its propensity to do so is less than that of mivacurium [64]. Unlike rapacuronium, gantacurium does not cause bronchoconstriction via interaction with M2 and M3 muscarinic receptors even at doses several times greater than those required for muscle paralysis in guinea pigs [65].

\section{CW002}

\section{Structure}

The unique pharmacology of gantacurium led to the development of nonhalogenated olefinic isoquinolinium compounds. The absence of chlorine in the compound results in less activation of the olefinic carbons, which are then influenced only by the two relatively weakly electronegative adjacent alpha-carboxyl (ester) groups located on both sides of the central olefinic double bond causing the adduction of 

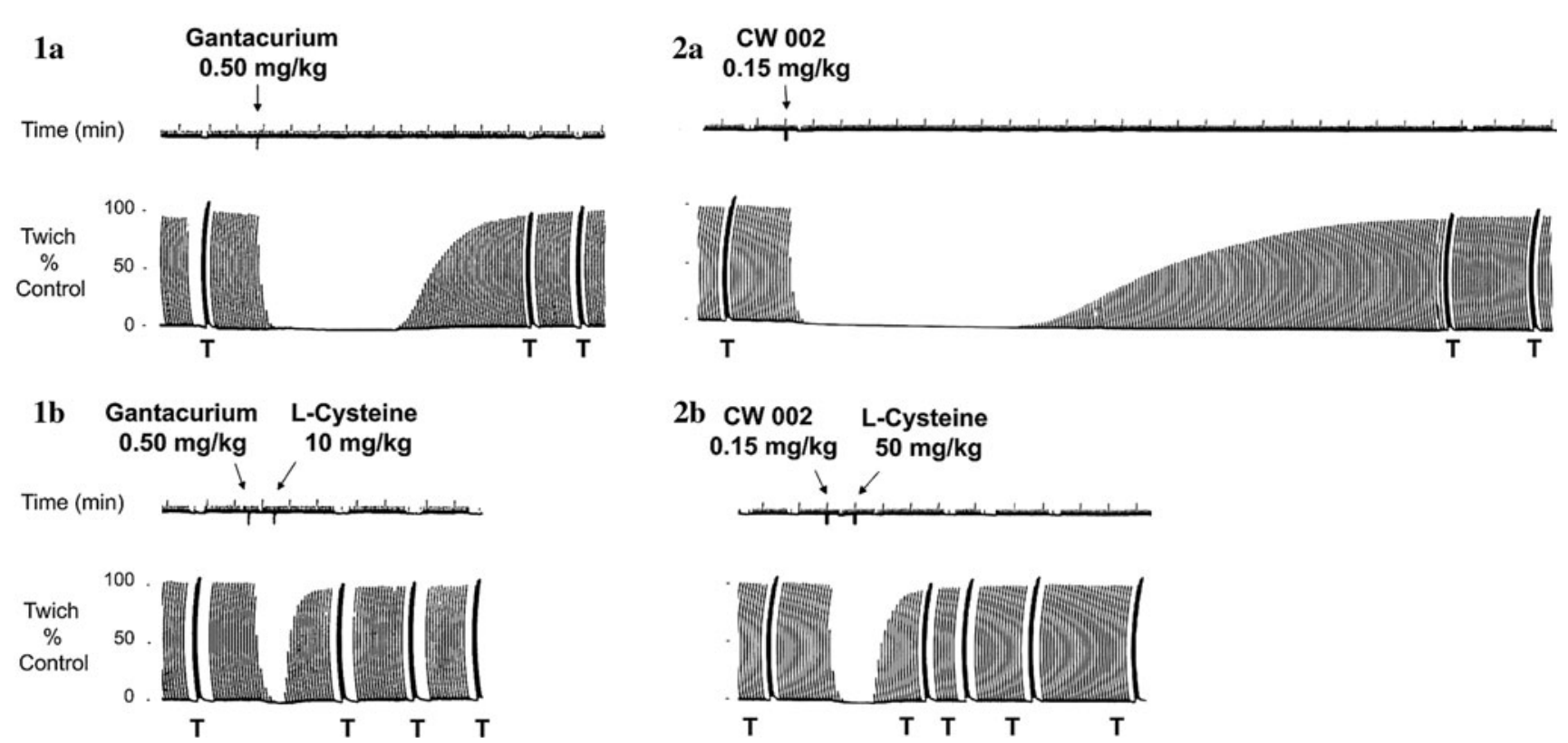

Fig. 2 Twitch recordings in individual monkeys demonstrating in 1a spontaneous recovery from gantacurium, $0.50 \mathrm{mg} / \mathrm{kg}$ and in $\mathbf{2 a}$ spontaneous recovery from CW002, $0.15 \mathrm{mg} / \mathrm{kg}$. Complete spontaneous recovery from gantacurium-induced block occurs in approximately $11 \mathrm{~min}$ and from CW002-induced block, $25 \mathrm{~min}$. Recovery is shortened by the administration of L-cysteine, as demonstrated in

panels $\mathbf{1 b}$ and $\mathbf{2 b}$. Administration of L-cysteine, $10 \mathrm{mg} / \mathrm{kg}, 1 \mathrm{~min}$ after $0.50 \mathrm{mg} / \mathrm{kg}$ gantacurium shortens the time from administration of the neuromuscular blocking agent to complete recovery from 11 to approximately $3 \mathrm{~min}$ in this one animal. As demonstrated in panel $\mathbf{2 b}$, administration of L-cysteine, $50 \mathrm{mg} / \mathrm{kg}, 1 \mathrm{~min}$ following CW002 shortened recovery from 25 to $4 \mathrm{~min}$

L-cysteine to occur more slowly. CW002, a nonhalogenated, symmetrical, benzylisoquinolinium fumarate diester compound, is the first of these compounds to undergo human trials. To date, ten volunteers have participated in the trial of this compound. Based on the results of animal trials and in vitro studies, its duration of action will be longer because of slower L-cysteine adduction.

\section{Pharmacology}

CW002 is a potent nondepolarizing neuromuscular blocking agent, with an $\mathrm{ED}_{95}$ in monkeys receiving isoflurane and nitrous oxide anesthesia of $0.042 \mathrm{mg} / \mathrm{kg}$ [61••]. The time from administration of an approximate $4 \times \mathrm{ED}_{95}$ dose of CW002 to recovery of $95 \%$ twitch height is $28 \mathrm{~min}$, approximately half that of cisatracurium $(58.0 \mathrm{~min})$ and three times longer than that of gantacurium (10.4 min). This appears comparable to recovery to a train-of-four ratio of $90 \%$ following administration of $5 \times \mathrm{ED}_{90}$ of rocuronium, which is $28 \mathrm{~min}$ [66]. The $5-95 \%$ recovery interval of CW002 after $4 \times \mathrm{ED}_{95}$ dose is $10.8 \mathrm{~min}$, shorter than that of cisatracurium following a $1.25 \times \mathrm{ED}_{95}$ dose $(20.3 \mathrm{~min})$.

\section{Reversal}

Neostigmine, $0.05 \mathrm{mg} / \mathrm{kg}$, will shorten recovery from CW002-induced neuromuscular block when administered

at moderate levels of neuromuscular block, $2 \%$ recovery of twitch height. It is not effective in antagonizing block when administered $1 \mathrm{~min}$ following administration of CW002. In contrast, L-cysteine, $30-50 \mathrm{mg} / \mathrm{kg}$, administered 1 min after $4 \times \mathrm{ED}_{95}$ of CW002 rapidly restores neuromuscular function in less than 3 min (Fig. 2). When administered at $2 \%$ recovery of twitch height, L-cysteine, $50 \mathrm{mg} / \mathrm{kg}$, also shortens the $5-95 \%$ recovery interval to $2.1 \mathrm{~min}$, which is significantly shorter than recovery following neostigmine $[61 \bullet \cdot]$.

\section{Adverse Effects}

CW002, like gantacurium, does not interact with M2 or M3 receptors of the airway [65]. Therefore, CW002 should not cause bronchoconstriction. Current clinical trials have been designed to look for changes in peak airway pressure that may, in the absence of a rise in histamine levels, be indicative of the occurrence of bronchoconstriction through this mechanism.

In dogs, sequential increasing dosing of CW002 to supratherapeutic levels produced a small but significant reduction of mean arterial pressure (MAP) [67]. In this model, dose-related reductions were also evident in heart rate and cardiac output starting at $50 \times \mathrm{ED}_{95}$ and mean pulmonary arterial pressure at $100 \times \mathrm{ED}_{95}$. In contrast to the direct relationship between the dose of CW002 and changes in hemodynamic variables, a similar relationship 
did not exist for histamine release. That may be due to the fact that for modeling in this study, administration of progressively larger doses of CW002, was not optimal to demonstrate histamine release. There is the possibility that with bolus administration of a larger single dose, histamine release will become apparent.

\section{L-Cysteine Reversal}

L-Cysteine is a nonessential amino acid in adults and conditionally essential in preterm infants because of the enzymatic immaturity of the trans-sulfuration pathways that convert methionine to cysteine [68]. As such, L-cysteine is commonly infused at doses up to $80 \mathrm{mg} / \mathrm{kg} / \mathrm{day}$ to supplement parenteral nutrition in preterm infants [69].

As previously described, the olefinic isoquinolinium diester compounds gantacurium and CW002 are chemically inactivated by the adduction of L-cysteine to its central double bond. L-cysteine adduction occurs at different rates in the compounds because of their different structures, accounting for their different durations of action. Intravenous administration of exogenous L-cysteine shortens recovery by increasing the amount of L-cysteine available to bind to the neuromuscular blocking agents.

The dose of L-cysteine required for rapid antagonism of $5 \times \mathrm{ED}_{95}$ of gantacurium is $10 \mathrm{mg} / \mathrm{kg}$. This dose is smaller than that required for rapid antagonism of $4 \times \mathrm{ED}_{95}$ of CW002, $50 \mathrm{mg} / \mathrm{kg}$ [61••]. This difference can be explained by the differences in structure of the compounds. The chlorine substitution in gantacurium accelerates L-cysteine adduction to the olefin, and is likely the reason it has ultrashort duration of action and is rapidly antagonized with administration of relatively low doses of L-cysteine. Of note, neuromuscular block induced by cisatracurium is not antagonized by L-cysteine.

L-Cysteine, in doses up through $50 \mathrm{mg} / \mathrm{kg}$, shows a dose-dependent relationship for antagonism of CW002 [70•] — with larger doses resulting in greater degrees of recovery $1 \mathrm{~min}$ after administration of L-cysteine. Administration of larger doses of L-cysteine does not further shorten any recovery parameter. When administered after reversal of CW002-induced block with L-cysteine, additional doses of CW002 have a shorter duration of action.

Increasing the dose of L-cysteine from 10 to $100 \mathrm{mg} / \mathrm{kg}$ tends to increase MAP and reduce the heart rate. The increases in MAP, though, are not clearly dose related. These hemodynamic changes are, on average, less than $10 \%$, even following administration of $100 \mathrm{mg} / \mathrm{kg} \mathrm{L-cys-}$ teine. There is a multiphasic response to administration of this large dose of L-cysteine, with an initial vasodilation followed by a more sustained vasoconstriction. The mechanism of this response remains unclear.
Toxicologic evaluation of L-cysteine in rats indicates that intraperitoneal administration of L-cysteine at doses 24-30 times greater than required for reversal of CW002induced block and 120-150 times greater than required for reversal of gantacurium-induced block are associated with acute neurotoxicity [71, 72]. Toxicologic studies in dogs demonstrate that a single $200-\mathrm{mg} / \mathrm{kg}$ dose of L-cysteine caused no mortality, morbidity, or weight loss during the observed period and no difference in hematologic, coagulation, and serum chemistry values 2 or 14 days after administration, when compared to control dogs. Animals that received repeated doses of L-cysteine, 10, 20, 50, and $100 \mathrm{mg} / \mathrm{kg}$, during a 4-week period for definition of the dose response relationship for reversal of CW002, maintained normal activity and behavior and had no change in appetite, weight loss, or morbid events.

\section{Conclusion}

Ongoing work related to the development of nondepolarizing neuromuscular blocking agents has allowed for the identification of an entirely new series of compounds. These compounds are potent nondepolarizing neuromuscular blockers that are inactivated at different rates, depending on their structure. Inactivation of these fumarates occurs through an entirely unique mechanism, that of cysteine adduction. Because of this, their effect can be reversed very rapidly through the administration of L-cysteine. Whether or not gantacurium or CW002 are introduced into clinical practice, they are likely the predecessors of similar compounds with even more favorable pharmacodynamic, kinetic and adverse effect profiles that will warrant study.

Disclosure Hiroshi Sunaga declares he has no conflict of interest. Cynthia A. Lien declares she has no conflict of interest.

\section{References}

Papers of particular interest, published recently, have been highlighted as:

- Of importance

- Of major importance

1. Savarese JJ, Kitz RJ. Does clinical anesthesia need new neuromuscular blocking agents? Anesthesiology. 1975;42:236-9.

2. Griffith HR, Johnson GE. The use of curare in general anesthesia. Anesthesiology. 1942;3:418-20.

3. Foldes FF, McNall PG, Borrego-Hinojosa JM. Succinylcholine: a new approach to muscular relaxation in anesthesiology. N Engl $\mathrm{J}$ Med. 1952;247:596-600. 
4. Feldman S, Fauvel N, Harrop-Griffiths AW. The onset of neuromuscular blockade in neuromuscular blocking agents: past, present and future. In: Bowman WC, Denissen PAF, Feldman S, editors. Princeton, New York: Excerpta Medica; 1990.

5. Fauvel NJ. Onset of neuromuscular block: the effect of biophase delay. Anaesth Pharmacol Rev. 1993;1:44-8.

6. Paton WD, Waud DR. The margin of safety of neuromuscular transmission. J Physiol. 1967;191:59-90.

7. Szalados JE, Donati F, Bevan DR. Effect of d-tubocurarine pretreatment on succinylcholine twitch augmentation and neuromuscular blockade. Anesth Analg. 1990;71:55-9.

8. Kopman AF, Klewicka MM, Neuman GG. An alternate method for estimating the dose-response relationships of neuromuscular blocking drugs. Anesth Analg. 2000;90:1191-7.

9. Bowman WC, Rodger IW, Houston J, et al. Structure:action relationships among some desacetoxy analogues of pancuronium and vecuronium in the anesthetized cat. Anesthesiology. 1988;69: 57-62.

10. Wastila WB, Maehr RB, Turner GL, et al. Comparative pharmacology of cisatracurium (51W89), atracurium, and five isomers in cats. Anesthesiology. 1996;85:169-77.

11. Kopman AF. Pancuronium, gallamine, and d-tubocurarine compared: is speed of onset inversely related to drug potency? Anesthesiology. 1989;70:915-20.

12. Bevan DR. Neuromuscular blocking drugs: onset and intubation. J Clin Anesth. 1997;9:36S-9S.

13. Roy JJ, Donati F, Boismenu D, et al. Concentration-effect relation of succinylcholine chloride during propofol anesthesia. Anesthesiology. 2002;97:1082-92.

14. Hickey DR, O'Connor JP, Donati F. Comparison of atracurium and succinylcholine for electroconvulsive therapy in a patient with atypical plasma cholinesterase. Can J Anaesth. 1987;34: 280-3.

15. Ali HH, Wilson RS, Savarese JJ, et al. The effect of tubocurarine on indirectly elicited train-of-four muscle response and respiratory measurements in humans. Br J Anaesth. 1975;47:570-4.

16. Engbaek J, Howardy-Hansen P, Ording H, et al. Precurarization with vecuronium and pancuronium in awake, healthy volunteers: the influence on neuromuscular transmission and pulmonary function. Acta Anaesthesiol Scand. 1985;29:117-20.

17. Howardy-Hansen P, Møller J, Hansen B. Pretreatment with atracurium: the influence on neuromuscular transmission and pulmonary function. Acta Anaesthesiol Scand. 1987;31:642-4.

18. Kopman AF, Yee PS, Neuman GG. Relationship of the train-offour fade ratio to clinical signs and symptoms of residual paralysis in awake volunteers. Anesthesiology. 1997;86:765-71.

19. Berg H, Roed J, Viby-Mogensen J. Residual neuromuscular block is a risk factor for postoperative pulmonary complications. A prospective, randomised, and blinded study of postoperative pulmonary complications after atracurium, vecuronium and pancuronium. Acta Anaesthesiol Scand. 1997;41:1095-103.

20. Eriksson LI, Sato M, Severinghaus JW. Effect of a vecuroniuminduced partial neuromuscular block on hypoxic ventilatory response. Anesthesiology. 1993;78:693-9.

21. •• Murphy GS, Szokol JW, Marymont JH. Residual neuromuscular blockade and critical respiratory events in the postanesthesia care unit. Anesth Analg. 2008;107:130-137. This study documents that in a surgical population, critical respiratory events, such as decreases in oxygen saturation, are associated with a train-of-four ratio less than $90 \%$.

22. • Murphy GS, Szokol JW, Avram MJ, et al. Intraoperative acceleromyography monitoring reduces symptoms of muscle weakness and improves quality of recovery in the early postoperative period. Anesthesiology. 2011;115:946-954. This study found that a residual neuromuscular block of less than a train-of-four ratio of $70 \%$ and between 70 and $90 \%$ occurred more frequently in patients monitored with qualitative monitors of neuromuscular function than those monitored with acceleromyographs.

23. Naguib M, Kopman AF, Lien CA, et al. A survey of current management of neuromuscular block in the United States and Europe. Anesth Analg. 2010;111:110-9.

24. Morris RB, Cahalan MK, Miller RD, et al. The cardiovascular effects of vecuronium (ORG NC45) and pancuronium in patients undergoing coronary artery bypass grafting. Anesthesiology. 1983;58:438-40.

25. Basta SJ, Ali HH, Savarese JJ, et al. Clinical pharmacology of atracurium besylate [BW 33A]: a new non-depolarizing muscle relaxant. Anesth Analg. 1982;61:723-9.

26. Basta SJ, Savarese JJ, Ali HH, et al. Histamine-releasing potencies of atracurium, dimethyl tubocurarine and tubocurarine. Br J Anaesth. 1983;55:105S-6S.

27. Booij LH, Knape HT. The neuromuscular blocking effect of Org 9426. A new intermediately acting steroidal non-depolarising muscle relaxant in man. Anaesthesia. 1991;46:341-3.

28. Foldes FF, Nagashima H, Nguyen HD, et al. The neuromuscular effects of ORG9426 in patients receiving balanced anesthesia. Anesthesiology. 1991;75:191-6.

29. Lambalk LM, De Wit AP, Wierda JM, et al. Dose-response relationship and time course of action of Org 9426. A new muscle relaxant of intermediate duration evaluated under various anaesthetic techniques. Anaesthesia. 1991;46:907-11.

30. Magorian T, Flannery KB, Miller RD. Comparison of rocuronium, succinylcholine, and vecuronium for rapid-sequence induction of anesthesia in adult patients. Anesthesiology. 1993;79: 913-8.

31. Belmont MR, Lien CA, Quessy S. The clinical neuromuscular pharmacology of $51 \mathrm{~W} 89$ in patients receiving nitrous oxide/ opioid/barbiturate anesthesia. Anesthesiology. 1995;82:1139-45.

32. Lien CA, Belmont MR, Abalos A, et al. The cardiovascular effects and histamine-releasing properties of 51W89 in patients receiving nitrous oxide/opioid/barbiturate anesthesia. Anesthesiology. 1995;82:1131-8.

33. Lien CA, Schmith VD, Embree PB, et al. The pharmacokinetics and pharmacodynamics of the stereoisomers of mivacurium in patients receiving nitrous oxide/opioid/barbiturate anesthesia. Anesthesiology. 1994;80:1296-302.

34. Savarese JJ, Ali HH, Basta SJ, et al. The clinical neuromuscular pharmacology of mivacurium chloride (BW B1090U). A shortacting nondepolarizing ester neuromuscular blocking drug. Anesthesiology. 1988;68:723-32.

35. Savarese JJ, Ali HH, Basta SJ, et al. The cardiovascular effects of mivacurium chloride (BW B1090U) in patients receiving nitrous oxide-opiate-barbiturate anesthesia. Anesthesiology. 1989;70: 386-94.

36. Wierda JM, Beaufort AM, Kleef UW, et al. Preliminary investigations of the clinical pharmacology of three short-acting non depolarizing neuromuscular blocking agents, Org 9453, Org 9489 and Org 9487. Can J Anaesth. 1984;41:213-20.

37. Schiere S, Proost JH, Schuringa M, et al. Pharmacokinetics and pharmacokinetic-dynamic relationship between rapacuronium (Org 9487) and its 3-desacetyl metabolite (Org 9488). Anesth Analg. 1999;88:640-7.

38. Jooste E, Klafter F, Hirshman CA, et al. A mechanism for rapacuronoum-induced bronchospasm: M2 muscarinic receptor antagonism. Anesthesiology. 2003;98:906-11.

39. Jooste EH, Sharma A, Zhang Y, et al. Rapacuronium augments acetylcholine-induced bronchoconstriction via positive allosteric interactions at the M3 muscarinic receptor. Anesthesiology. 2005;103:1195-203.

40. Jooste E, Zhang Y, Emala CW. Neuromuscular blocking agents' differential bronchoconstrictive potential in guinea pig airways. Anesthesiology. 2007;106:763-72. 
41. Rajchert DM, Pasquariello CA, Watcha MF, et al. Rapacurnium and the risk of bronchospasm in pediatric patients. Anesth Analg. 2002;94:488-93.

42. Bom A, Bradley M, Cameron K, et al. A novel concept of reversing neuromuscular block: chemical encapsulation of rocuronium bromide by a cyclodextrin-based synthetic host. Angew Chem Int Ed Engl. 2002;41:266-70.

43. Epemolu O, Bom A, Hope F, et al. Reversal of neuromuscular blockade and simultaneous increase in plasma rocuronium concentration after in the intravenous infusion of the novel reversal agent Org 25969. Anesthesiology. 2003;99:632-7.

44. Gijsenbergh F, Ramael S, Houwing N, et al. First human exposure of Org 25969, a novel agent to reverse the action of rocuronium bromide. Anesthesiology. 2005;103:695-703.

45. Jones RK, Caldwell JE, Brull SJ, et al. Reversal of profound rocuronium-induced blockade with sugammadex: a randomized comparison with neostigmine. Anesthesiology. 2008;109:816-24.

46. Cammu G, Van Vlem B, van den Heuvel M, et al. Dialysability of sugammadex and its complex with rocuronium in intensive care patients with severe renal impairment. Br J Anaesth. 2012; 109:382-90.

47. Sparr HJ, Vermeyen KM, Beaufort AM, et al. Early reversal of profound rocuronium-induced neuromuscular blockade by sugammadex in a randomized multicenter study: efficacy, safety, and pharmacokinetics. Anesthesiology. 2007;106:935-43.

48. - Fuchs-Buder T. Less is not always more: sugammadex and the risk of under-dosing. Eur J Anaesthesiol. 2010;27:849-850. This report documents that, while sugammadex will shorten recovery of neuromuscular function, appropriate doses of the reversal agent have to be administered to guarantee complete recovery of neuromuscular function.

49. Rose M, Fisher M. Rocuronium: high risk for anaphylaxis? Br J Anaesth. 2001;86:678-82.

50. Mertes PM, Laxenaire MC, Alla F. Groupe d'Etudes des Réactions Anaphylactoïdes Peranesthésiques.: Anaphylactic and anaphylactoid reactions occurring during anesthesia in France in 1999-2000. Anesthesiology. 2003;99:536-45.

51. Bhananker SM, O'Donnell JT, Salemi JR, et al. The risk of anaphylactic reactions to rocuronium in the United States is comparable to that of rocuronium: an analysis of food and drug administration reporting of adverse events. Anesth Analg. 2005;101:819-22.

52. McDonnell NJ, Pavy TJ, Green LK, et al. Sugammadex in the management of rocuronium-induced anaphylaxis. Br J Anaesth. 2011;106:199-201.

53. Funnell AE, Griffiths J, Hodzovic I. A further case of rocuronium-induced anaphylaxis treated with sugammadex. Br J Anaesth. 2011;107:275-6.

54. Kawano T, Tamura T, Hamaguchi M, et al. Successful management of rocuronium-induced anaphylactic reactions with sugammadex: a case report. J Clin Anesth. 2012;24:62-4.

55. Barthel F, Stojeba N, Lyons G, et al. Sugammadex in rocuronium anaphylaxis: dose matters. Br J Anaesth. 2012;109:646-7.

56. • Leysen J, Bridts CH, De Clerck LS, et al. Rocuronium-induced anaphylaxis is probably not mitigated by sugammadex: evidence from as in vitro experiment. Anaesthesia. 2011;66:526-527. A demonstration that even though sugammadex encapsulates rocuronium, which is an allergen in some patients, it does not lessen the severity of anaphylaxis.

57. Clarke RC, Sadleir PH, Platt PR. The role of sugammadex in the development and modification of an allergic response to rocuronium: evidence from a cutaneous model. Anaesthesia. 2012;67: 266-73.
58. Menéndez-Ozcoidi L, Ortiz-Gómez JR, Olaguibel-Ribero JM, et al. Allergy to low dose sugammadex. Anaesthesia. 2011;66: 217-9.

59. Godai K, Hasegawa-Moriyama M, Kuniyoshi $\mathrm{T}$, et al. Three cases of suspected sugammadex-induced hypersensitivity reactions. Br J Anaesth. 2012;109:216-8.

60. Savarese JJ, Belmont MR, Hashim MA, et al. Preclinical pharmacology of GW280430A (AV430A) in the rhesus monkey and in the cat: a comparison with mivacurium. Anesthesiology. 2004;100:835-45.

61. • Savarese JJ, McGilvra JD, Sunaga H, et al. Rapid chemical antagonism of neuromuscular blockade by L-cysteine adduction to and inactivation of the olefinic (double-bonded) isoquinolinium diester compounds gantacurium (AV430A), CW002, and CW011. Anesthesiology. 2010;113:58-73. This was the first report detailing the unique means of inactivation of gantacurium and CW002. The study also demonstrated that administration of L-cysteine shortened the already rapid recovery of neuromuscular function after administration of these neuromuscular blocking agents.

62. Belmont MR, Lien CA, Tjan J, et al. Clinical pharmacology of GW280430A in humans. Anesthesiology. 2004;100:768-73.

63. - Lien CA, Savard P, Belmont M, et al. Fumarates: unique nondepolarizing neuromuscular blocking agents that are antagonized by cysteine. J Crit Care. 2009;24:50-57. This was an early review of development of the fumarates.

64. Lien CA, Belmont MR, Heerdt PM. GW280430A: pharmacodynamics and potential adverse effects. Anesthesiology. 2005; 102:862-3.

65. Sunaga H, Zhang Y, Savarese JJ, et al. Gantacurium and CW002 do not potentiate muscarinic receptor-mediated airway smooth muscle constriction in guinea pigs. Anesthesiology. 2010;112: 892-9.

66. de Boer HD, van Egmond J, van de Pol F, et al. Reversal of profound rocuronium neuromuscular blockade by sugammadex in anesthetized rhesus monkeys. Anesthesiology. 2006;104: 718-23.

67. Heerdt PM, Malhotra JK, Pan BY, et al. Pharmacodynamics and cardiopulmonary side effects of CW002, a cysteine-reversible neuromuscular blocking drug in dogs. Anesthesiology. 2010;112: $910-6$.

68. Valentine CJ, Puthoff TD. Enhancing parenteral nutrition therapy for the neonate. Nutr Clin Pract. 2007;22:183-93.

69. Zlotkin SH, Bryan MH, Anderson GH. Cysteine supplementation to cysteine-free intravenous feeding regimens in newborn infants. Am J Clin Nutr. 1981;34:914-23.

70. - Sunaga H, Malhotra JK, Yoon E, et al. Cysteine reversal of the novel neuromuscular blocking drug CW002 in dogs: pharmacodynamics, acute cardiovascular effects, and preliminary toxicology. Anesthesiology. 2010; 12:900-909. A description of the reversal of CWOO2 induced neuromuscular block through administration of L-cysteine. The study demonstrated that a dose of $50 \mathrm{mg} / \mathrm{kg}$ resulted in the most rapid recovery of neuromuscular function when administered 1 min after CWOO2 and that further increases in dose did not result in shorter recovery of neuromuscular function. Large doses of L-cysteine were not associated with toxic effects.

71. Shapre LG, Olney JW, Ohlendorf C, et al. Brain damage and associated behavioral deficits following the administration of Lcysteine to infant rats. Pharmacol Biochem Behav. 1975;3:291-8.

72. Sawamoto O, Hagiwara R, Kurisu K. L-Cysteine-induced brain damage in adult rats. Exp Toxicol Pathol. 2004;56:45-52. 